\title{
A life cycle assessment of the cradle-to-gate phases of clay brick production in South Africa
}

\author{
G. A. Rice \& P. T. Vosloo \\ Department of Architecture, University of Pretoria, South Africa
}

\begin{abstract}
Quantified environmental impacts associated with clay brick production are not very well researched for the South African context. This paper, based on a study undertaken for the Clay Brick Association of South Africa, where clay bricks are still the predominant wall construction material, identifies processes within the various clay brick firing techniques, where environmental impacts are the most severe, with the intention to make producers aware of where they may improve production processes and reduce adverse environmental impacts. The paper will focus on the research results of the cradle-to-gate phase of the life cycle of clay bricks. The data collected from the full population survey were used to identify and model the environmental impacts using SimaPro software and the EcoInvent database. The results for the full industry (averaged across firing technologies) per $\mathrm{kg}$ of fired clay brick for the impact categories assessed are: carcinogens $0.007315 \mathrm{~kg} \mathrm{C}_{2} \mathrm{H}_{3} \mathrm{Cl}$ eq, non-carcinogens $0.031052 \mathrm{~kg} \mathrm{C}_{2} \mathrm{H}_{3} \mathrm{Cl}$ eq, respiratory inorganics $0.000426 \mathrm{~kg}$ PM2.5 eq, ionizing radiation $1.070064 \mathrm{~Bq} \mathrm{C}-14 \mathrm{eq}$, ozone layer depletion $<0.0000 \mathrm{~kg} \mathrm{CFC}-11 \mathrm{eq}$, respiratory organics $0.000076 \mathrm{~kg} \mathrm{C}_{2} \mathrm{H}_{4}$ eq, aquatic ecotoxicity $77.239 \mathrm{~kg}$ TEG water, terrestrial ecotoxicity $21.27 \mathrm{~kg}$ TEG soil, terrestrial acidification/nitrification $0.0088 \mathrm{~kg} \mathrm{SO}_{2}$ eq, land occupation $0.001759 \mathrm{~m}^{2}$ org.arable, aquatic acidification $0.004045 \mathrm{~kg} \mathrm{SO} \mathrm{SO}_{2}$ eq, aquatic eutrophication $0.000150 \mathrm{~kg} \mathrm{PO}_{4} \mathrm{P}$-lim, global warming $0.853033 \mathrm{~kg} \mathrm{CO}_{2}$ eq, nonrenewable energy 8.99914 MJ primary and mineral extraction $0.000558 \mathrm{MJ}$ surplus. Overall, the findings suggest that there is great potential to improve the clay brick manufacturing industry in terms of its environmental impacts.

Keywords: life cycle assessment, cradle-to-gate, clay brick, environmental impact, SimaPro.
\end{abstract}




\section{Introduction}

The issue of sustainability has become increasingly critical in the current climatic and economic environment. In the 1987 Bruntland Report, the UN's World Commission on Environment and Development defined sustainability as meeting the needs of the present generation without compromising the ability of future generations to meet their needs [1].

Sustainability can also be defined as the balance needed between the gratification of present needs and the concern for the well-being of future generations [2]. This definition also alludes to the fact that although we deplete natural resources at the expense of future generations, we also generate capital and knowledge which raise the well-being of future generations.

The greatest contributor to achieve sustainability will be to reduce the global environmental changes earth is experiencing due to anthropogenic climate change. Man has evolved in such a way that little consideration is placed on earth's finite resources and the impacts development has had on the environment.

Construction is a major source of global greenhouse gas emissions, both during the manufacturing stages of building materials and in the operational phase of the building [3]. The building sector consumes between $30 \%$ and $45 \%$ of global energy production, with about $20 \%$ of that on the construction of the building and $80 \%$ during the operational phase of the building [4].

\subsection{Scope of the study}

The developing South African construction industry is dominated by two construction typologies: concrete frame and brick infill construction and load bearing brick construction. Other technologies such as light steel frame construction, timber construction and combination construction have traditionally been less used.

South Africa produced 450 million tonnes of $\mathrm{CO}_{2}$ in 2009 , placing it as the 12 th greatest $\mathrm{CO}_{2}$ emitter globally [5]. South Africa's $\mathrm{CO}_{2}$ emission breakdown is dominated by transport at $16 \%$ and manufacturing at $40 \%$ [6]. Manufacturing includes the production of building materials, which contributes 18 million tonnes $\mathrm{CO}_{2}$ per year to South Africa's emissions, $40 \%$ of this $\mathrm{CO}_{2}$ is attributed to the manufacture of clay bricks [6].

\subsection{Problem statement}

The environmental impacts from the production and manufacture of clay bricks for the South African industry are not known; there is currently no published comprehensive research on the clay brick manufacturing industry's environmental impacts and this study attempted to fill this knowledge gap through the implementation of a life cycle assessment (LCA). 


\section{Research methodology}

The research employed a quantitative methodology through a field survey of the total population and modelling using an internationally recognised and accepted LCA software model.

\subsection{Population}

The field survey targeted the full population of South African clay brick manufacturers that implement all the various clay brick firing technologies. Primary data were obtained from over $84 \%$ of the population.

The full population is made up of 102 manufacturers using six different firing technologies; all of which use very much the same production processes with the only difference being in the firing stage. Clamp kilns fire bricks in open air pyramid like structures of stacked green bricks. Tunnel kilns fire bricks in a closed natural gas/refined oil fired kiln. Transverse Arch (TVA) kilns are characterized by a continual insertion and removal of green and fired bricks in a continually coal-fired system of adjacent arched brick kilns. The Hoffman kiln is a circular tunnel constructed out of refractory brick with a continual coal supply shifting the fire along the tunnel. The Vertical Shaft Brick Kiln (VSBK) is a continually coalfired shaft structure into which green bricks are hoisted at the top and removed once fired at the base. A Zigzag kiln is a continually coal-fired tunnel-like structure; the fire is moved through the zigzag shaped tunnel using fans. A breakdown of the population's firing technologies is shown in Table 1 .

Table 1: Breakdown of the clay brick manufacturers' firing technologies.

\begin{tabular}{|c|c|c|c|c|c|c|}
\hline Technology & Clamp & Tunnel & TVA & Hoffman & VSBK & Zigzag \\
\hline $\begin{array}{c}\text { Percentage of } \\
\text { population }\end{array}$ & $68 \%$ & $20 \%$ & $6 \%$ & $2 \%$ & $2 \%$ & $2 \%$ \\
\hline
\end{tabular}

\subsection{Research strategy}

The data collection phase followed a literature review which revealed pertinent aspects of similar projects and consisted of the questionnaire design, ethical clearance, pre-testing followed by the field survey. The collected data were allocated to a predetermined set of manufacturing processes to better group the stages of production, which facilitated the process of LCA modelling. Preliminary statistical analyses were done to configure the collected data into the format required for LCA modelling in the SimaPro software.

\subsection{Research delimitations}

The study was delimited to the processes involved from raw material extraction to the gate of the manufacturing plant. Environmental impacts associated with the transport to site, construction, operational and end of life stages were not modelled. The format of the study is based on the LCA guidelines suggested in ISO 14040:2006 [7]. 


\section{Life cycle assessment}

\subsection{Goal and scope definition}

The purpose of the study was to assess the environmental impacts associated with the production of clay bricks in South Africa and is intended to be used as a baseline project for the subsequent stages of the life cycle of clay bricks, i.e. the use, demolition, waste and recycle phases.

The intended audience of the study includes LCA consultants, professions in the building industry, with particular reference to architects, specification writers as well as the clay brick manufacturers.

\subsection{Product system description}

The product system for this study started with raw material extraction and ended with bricks at the production plant gate which covered the following stages: raw material extraction, raw material processing, clay preparation, extrusion and forming, brick drying, brick firing and off packing.

The primary function of a clay brick is to provide a construction component with a defined set of thermal and structural principles which may be used in conjunction with other bricks and building materials to construct a wall or barrier between indoor and outdoor environments.

\subsection{Reference flow and functional unit}

The reference flow for this product system is one kilogram of fired clay brick. The functional unit for the product system is one standard brick equivalent (SBE) which is defined as a unit of $2,75 \mathrm{~kg}$ of fired clay with a compressive strength between 12.5 and $17 \mathrm{MPa}$.

\subsection{System boundary}

The system boundary for this study is shown in Figure 1 and is defined by ISO 14040:2006 as the definition of the unit processes to be included in the system.

\subsection{Allocation approach}

Minimal allocation needed to be applied in this study as per ISO 14040:2006. Very few respondents in the study perform multi-output operations; therefore an allocation definition was not deemed necessary. Production plants which produce more than one product already provided a mass breakdown of all elementary flows to and from the different outputs. The data from these plants were treated as a single output plant as the data did not need to be allocated.

\subsection{Data requirements and data quality}

Data which were not available from the clay brick manufacturers' responses were sourced from the EcoInvent v2.2 database via SimaPro. Whereas the data obtained 


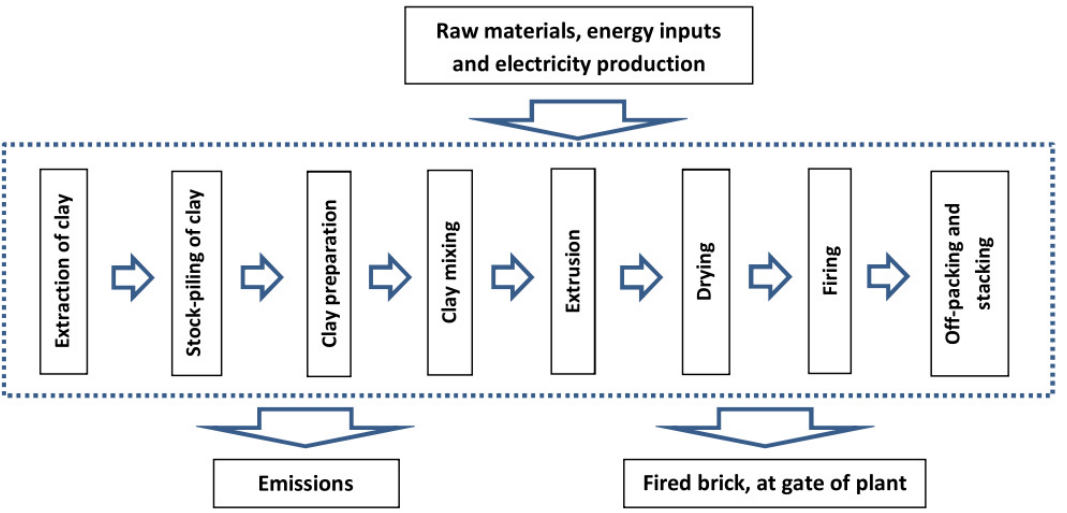

Figure 1: System boundary of the study.

from the field survey questionnaires were considered of the highest quality, data obtained from the EcoInvent were assumed to be of acceptable quality; it being peer reviewed before being incorporated in the database.

\subsection{Impact assessment method}

The inventory, developed from the data collection and subsequent modelling, identified certain environmental impacts through an assessment process within SimaPro. The impact assessment method selected for this study is Impact 2002+ which was selected as it proposes a feasible implementation of a combined midpoint/damage-orientated approach. Impact 2002+ assesses the following environmental impacts: carcinogens, non-carcinogens, respiratory inorganics, ionizing radiation, ozone layer depletion, respiratory organics, aquatic ecotoxicity, terrestrial eco-toxicity, terrestrial acidification, land occupation, global warming, non-renewable energy and mineral extraction.

\subsection{Interpretation of the identified impacts}

An interpretation of the main contributors to the environmental impacts was performed to identify the source of the greatest environmental impact from the assessed production processes.

\subsection{Life cycle inventory (LCI)}

The main data categories surveyed were land use, water use, energy use and waste creation, the latter included emissions, landfill and pollution. It was found feasible to use one questionnaire for all manufacturers, and even though their firing technologies differ, environmental inputs and outputs to and from all technologies are very similar. Selected aspects from the collected inventory for the life cycle model are presented in Table 2 below. 


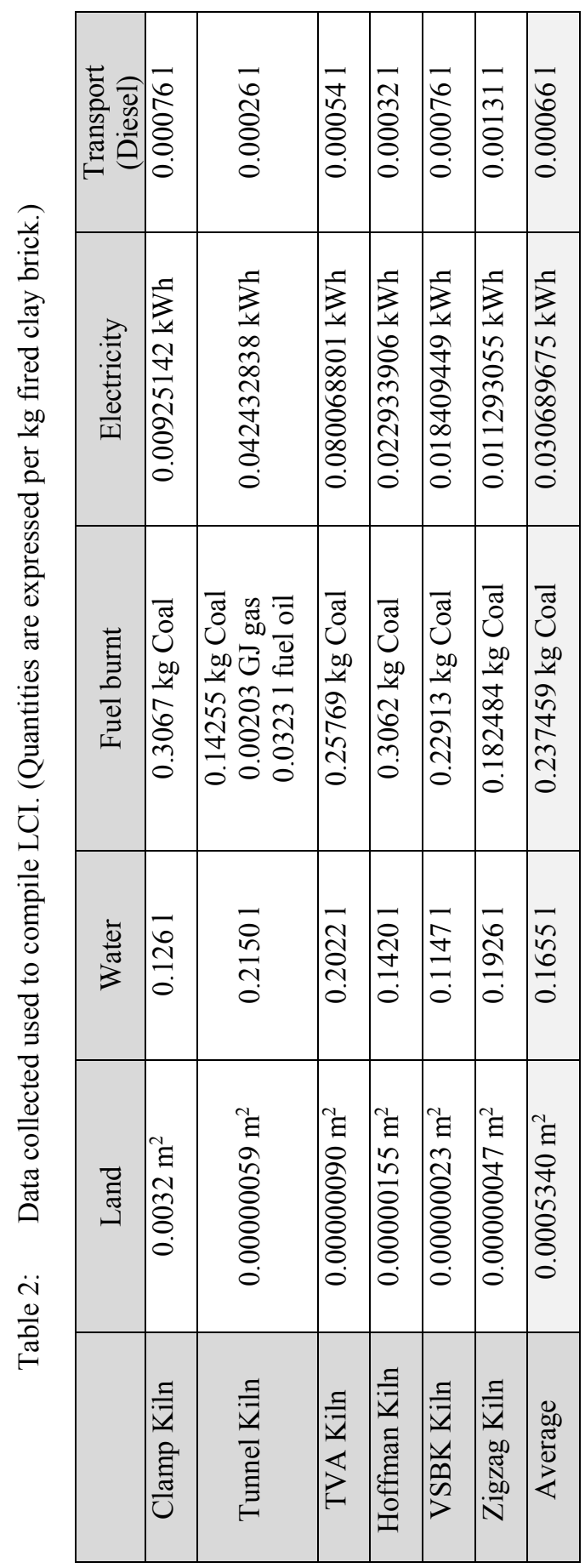




\subsection{Life cycle impact assessment}

The emissions of the modelled system are grouped into 15 environmental impacts according to Impact 2002+. The averaged environmental impacts associated with the production of clay bricks in South Africa are presented in Table 3 below.

Table 3: Environmental impact contributions averaged across all firing technologies.

\begin{tabular}{|c|c|c|c|}
\hline \multicolumn{2}{|r|}{ Impact category } & Unit & $\begin{array}{l}\text { Quantity (emitted per } \\
\text { kg fired clay brick) }\end{array}$ \\
\hline 1 & Carcinogens & $\mathrm{kg} \mathrm{C}_{2} \mathrm{H}_{3} \mathrm{Cl}$ eq & 0.007315 \\
\hline 2 & Non-carcinogens & $\mathrm{kg} \mathrm{C}_{2} \mathrm{H}_{3} \mathrm{Cl}$ eq & 0.031052 \\
\hline 3 & Respiratory inorganics & $\mathrm{kg}$ PM $2.5 \mathrm{eq}$ & 0.000426 \\
\hline 4 & Ionizing radiation & $\mathrm{Bq} \mathrm{C}-14 \mathrm{eq}$ & 1.070064 \\
\hline 5 & Ozone layer depletion & kg CFC-11 eq & 0.000000 \\
\hline 6 & Respiratory organics & $\mathrm{kg} \mathrm{C}_{2} \mathrm{H}_{4} \mathrm{eq}$ & 0.000076 \\
\hline 7 & Aquatic ecotoxicity & kg TEG water & 77.239618 \\
\hline 8 & Terrestrial ecotoxicity & kg TEG soil & 21.268101 \\
\hline 9 & Terrestrial acidification & $\mathrm{kg} \mathrm{SO}_{2} \mathrm{eq}$ & 0.008790 \\
\hline 10 & Land occupation & $\mathrm{m}^{2}$ org.arable & 0.001759 \\
\hline 11 & Aquatic acidification & $\mathrm{kg} \mathrm{SO}_{2} \mathrm{eq}$ & 0.004045 \\
\hline 12 & Aquatic eutrophication & $\mathrm{kg} \mathrm{PO}_{4} \mathrm{P}-\mathrm{lim}$ & 0.000150 \\
\hline 13 & Global warming & $\mathrm{kg} \mathrm{CO}_{2}$ eq & 0.853033 \\
\hline 14 & Non-renewable energy & MJ primary & 8.999114 \\
\hline 15 & Mineral extraction & MJ surplus & 0.000558 \\
\hline
\end{tabular}

\subsection{Normalization of results for comparison}

Figure 2 below shows the normalization results for selected impact categories across all firing technologies. Normalization allows interpretation of results by comparing the different categories with the same units on the same graph. Normalization is performed by dividing the impact by the respective normalization factor. The normalization is a ratio of the total impact of a specific category and the total European population [8]. It was deemed satisfactory to use these normalization factors as there are currently no geographically specific factors for South Africa. The normalization of results is expressed as the impact caused by a Unitarian emission that is equivalent to the impact generated by the given number of persons per year (person. year/Unitarian emission$_{\text {). }}$. 


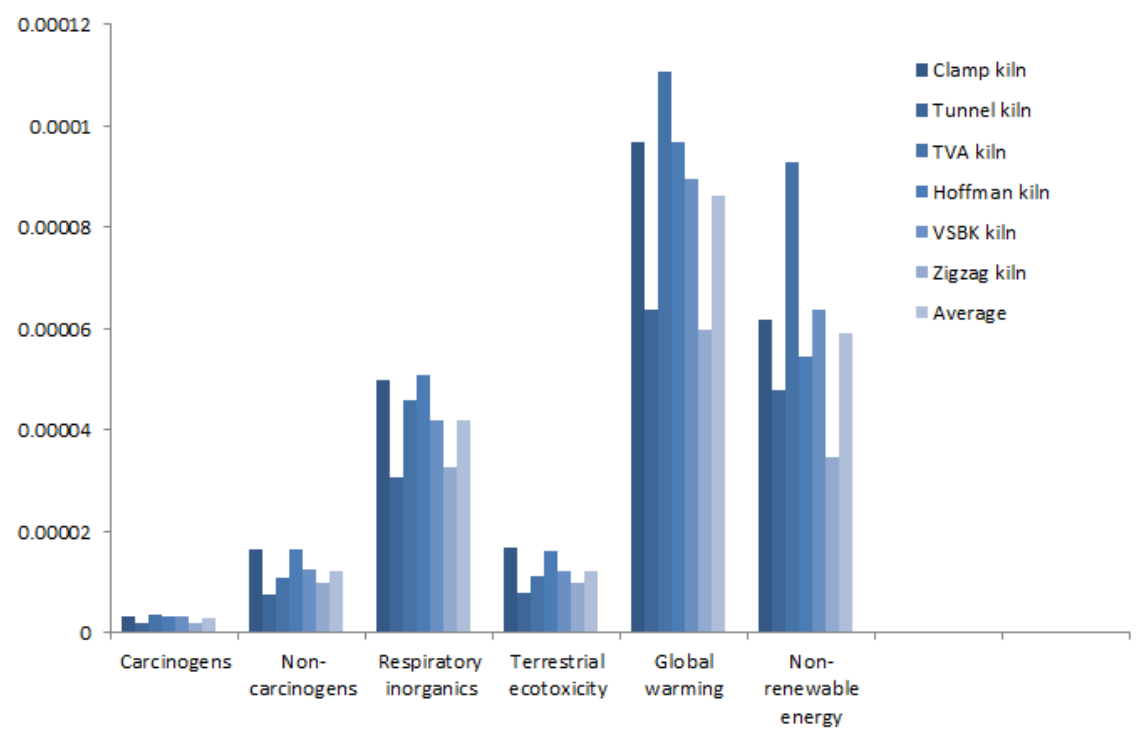

Figure 2: Normalization results for selected environmental impact categories.

\subsection{Characterization of results}

Table 4 shows the characterization results for all firing technologies in the clay brick production industry in South Africa. The total impact from the industry for the annual production of 9611178 Tons fired clay brick is reported in Table 4.

\subsection{Interpretation}

\subsubsection{Significant issues}

The results from the impact assessment show the impact each firing technology has on the assessed impact categories. Table 5 shows the severity of firing technologies on all impact categories. An assessment of the severity results show that the TVA kiln has the greatest environmental impact across most impact categories while the Tunnel kiln poses the least environmental impacts across the impact categories. These results should be read with an understanding of the population breakdown in order to evaluate the impacts.

The impact assessment reveals the unit processes or stages within the cradleto-gate life cycle of clay bricks in South Africa which has the greatest impact on the environment. For all the firing technologies using coal as the firing fuel, the most severe impacts come from the firing stage unit process, where internal body fuel and external burning fuel release the following emissions into the atmosphere per kg of fired clay brick, refer to Table 6. 


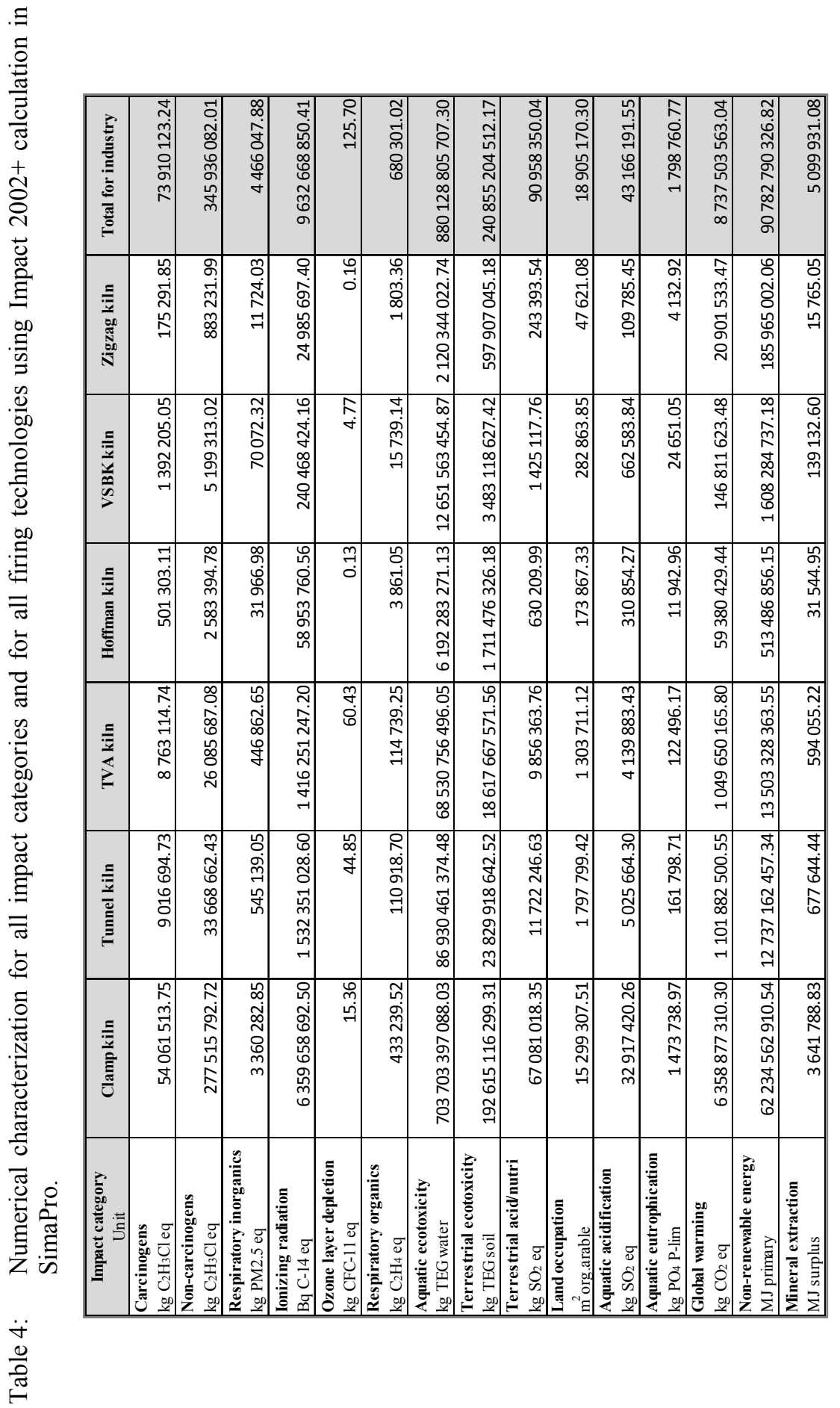

WIT Transactions on Ecology on The Built Environment, Vol 142, (C) 2014 WIT Press www.witpress.com, ISSN 1743-3509 (on-line) 
Table 5: Highest and lowest severity of all firing technologies for all impact categories per $\mathrm{kg}$ fired clay brick.

\begin{tabular}{|l|l|c|c|}
\hline \multicolumn{2}{|c|}{ Impact category } & $\begin{array}{c}\text { Most severe } \\
\text { contributing firing } \\
\text { technology }\end{array}$ & $\begin{array}{c}\text { Least severe } \\
\text { contributing firing } \\
\text { technology }\end{array}$ \\
\hline 1 & Carcinogens & TVA & Zigzag \\
\hline 2 & Non-carcinogens & Clamp & Tunnel \\
\hline 3 & Respiratory inorganics & Hoffman & Tunnel \\
\hline 4 & Ionizing radiation & TVA & Zigzag \\
\hline 5 & Ozone layer depletion & TVA & Hoffman \\
\hline 6 & Respiratory organics & TVA & Zigzag \\
\hline 7 & Aquatic ecotoxicity & Clamp & Tunnel \\
\hline 8 & Terrestrial ecotoxicity & Clamp & Tunnel \\
\hline 9 & Terrestrial acidification & TVA & Tunnel \\
\hline 10 & Land occupation & Hoffman & Tunnel \\
\hline 11 & Aquatic acidification & Hoffman & Tunnel \\
\hline 12 & Aquatic eutrophication & Clamp & Tunnel \\
\hline 13 & Global warming & TVA & Zigzag \\
\hline 14 & Non-renewable energy & TVA & Zigzag \\
\hline 15 & Mineral extraction & VSBK & Tunnel \\
\hline
\end{tabular}

Table 6: Emissions data from coal combustion for $1 \mathrm{~kg}$ of fired clay brick*

\begin{tabular}{|l|l|}
\hline Substance & Quantity \\
\hline Carbon dioxide & $0.095 \mathrm{~kg}$ \\
\hline Carbon monoxide & $0.005 \mathrm{~kg}$ \\
\hline Sulphur dioxide & $0.00044 \mathrm{~kg}$ \\
\hline Polonium-210 & $0.000085 \mathrm{~kg}$ \\
\hline Radium-228 & $0.000065 \mathrm{~kg}$ \\
\hline Nitrogen oxides & $0.000060 \mathrm{~kg}$ \\
\hline Lead-210 & $0.000046 \mathrm{~kg}$ \\
\hline Particulates $>10 \mu \mathrm{m}$ & $0.000035 \mathrm{~kg}$ \\
\hline Silicon & $0.0000158 \mathrm{~kg}$ \\
\hline Hydrogen chloride & $0.0000152 \mathrm{~kg}$ \\
\hline Methane & $0.000015 \mathrm{~kg}$ \\
\hline
\end{tabular}

*Proxy data was used as a basis for developing the emissions data used in the model (highest 10 contributors to emissions shown here).

\subsubsection{Sensitivity, consistency and completeness checks}

Sensitivity analyses were carried out on the model to assess the impact of emissions data, water use, mass of clay, electricity consumption split between unit processes and transport of firing fuel to manufacturing plant. Data obtained from literature are estimates for the South African context; this includes emissions from burning coal. Analyses showed little variation, this is due to the fact that the 
full population was surveyed and actual figures were recorded in the field survey. It can therefore be concluded that the data represented in the LCA model are accurate and a true reflection of the clay brick industry in South Africa.

Consistency and completeness checks were carried to ensure complete data was utilized in the LCA model. Consistency was achieved through invariable questionnaires being utilized in the field survey process as well as the disregarding incomplete questionnaires. Infrastructure processes were excluded from data collected. Literature data were sourced from a single database to ensure consistent reviewing. Geographically specific data was used where possible.

\section{Conclusions}

The research shows that the production of clay bricks in South Africa is heavily energy intensive. Most of the emissions generated from the cradle-to-gate stages are attributed to burning fuel during the firing process on the production site where coal is combusted in order to vitrify the clay bricks. The greatest environmental impact is the use of non-renewable energy sources; in this case from the high use of fossil fuels for firing bricks or electricity which is sourced from the South African electricity grid, which in turn is generated almost entirely by coal powered power stations.

The research shows that continually fired kilns have lower environmental impacts. It is advisable for manufacturers that currently utilise kilns that require start up for each batch of bricks to investigate and eventually invest in continually fired kiln technologies such as Zigzag kilns and Tunnel kilns.

\section{References}

[1] Morris, N. Sustainability: What is it? IEE Power Engineer. Oct/Nov, 11, 2004.

[2] Kulman, T. \& Farrington, J. What is Sustainability? Sustainability, 2, 34363448, 2010.

[3] Zipplies, R. Bending the Curve. Cape Town: Africa Geographic (Pty) Ltd, 2008.

[4] United Nations Environmental Programme, Buildings can play a key role in Combating Climate Change. Online available at http://www.unep.org /Documents.Multilingual/Default.Print.asp?DocumentID=502\&ArticleID $=5$ 545\&l=en 2007.

[5] McCormick, M. \& Scruton, P. An Atlas of Pollutions: the world in Carbon Dioxide Emissions. Online available at: http://e360.yale.edu/images/digest /carbon web.pdf 2009.

[6] Milford, R. Greenhouse Gas Emissions Baselines and Reduction Potentials from Buildings in South Africa. Paris: United Nations Environment Programme, 2007.

[7] International Standards Organization. Environmental management-Life cycle assessment-principles and framework. ISO 14040: 2006.

[8] Humbert, S. Impact 2002+. Quantis. Online available at: http://www.quantisintl.com/impact2002.php, 2009. 